From the Fred Hutchinson Cancer Research Center; University of Washington School of Medicine; Veterans Affairs Puget Sound Health Care System, Seattle, WA; Stanford University, Stanford; City of Hope-Kaiser Permanente Medical Group, Duarte, CA; Emory University, Atlanta, GA; University of Utah; Latter Day Saints Hospital, Salt Lake City, UT; Medical College of Wisconsin, Milwaukee, Wl; Oregon Health \& Science University, Portland, OR; Rocky Mountain Cancer Center, Denver, CO; Baylor University, Dallas, TX; University of Arizona, Tucson, AZ; University of Leipzig, Leipzig; University of Tübingen, Tübingen, Germany; and University of Torino, Torino, Italy.

Submitted November 16, 2009; accepted January 27, 2010; published online ahead of print at www.jco.org on May 3, 2010

Supported by Grants No. CA78902, HL36444, CA18029, CA15704, and CA106177 from the National Institutes of Health, Bethesda, MD.

Authors' disclosures of potential conflicts of interest and author contributions are found at the end of this article.

Corresponding author: Brenda M. Sandmaier, MD, Fred Hutchinson Cancer Research Center, 1100 Fairview Ave N, Mail Stop D1-100, PO Box 19024, Seattle, WA 98109-1024; e-mail: bsandmai@fhcrc.org

(c) 2010 by American Society of Clinical Oncology

0732-183X/10/2817-2859/\$20.00

DOI: 10.1200/JCO 2009.27.1460

\title{
Nonmyeloablative Allogeneic Hematopoietic Cell Transplantation in Patients With Acute Myeloid Leukemia
}

Boglarka Gyurkocza, Rainer Storb, Barry E. Storer, Thomas R. Chauncey, Thoralf Lange, Judith A. Shizuru, Amelia A. Langston, Michael A. Pulsipher, Christopher N. Bredeson, Richard T. Maziarz, Benedetto Bruno, Finn B. Petersen, Michael B. Maris, Edward Agura, Andrew Yeager, Wolfgang Bethge, Firoozeh Sahebi, Frederick R. Appelbaum, David G. Maloney, and Brenda M. Sandmaier

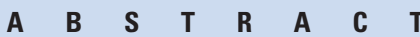

\section{Purpose}

Allogeneic hematopoietic cell transplantation (HCT) after high-dose conditioning regimens imposes prohibitively high risks of morbidity and mortality for patients with high-risk acute myeloid leukemia $(A M L)$ who are older or have comorbid conditions. Here, we examined outcomes after nonmyeloablative allogeneic HCT in such patients.

\section{Patients and Methods}

Two hundred seventy-four patients (median age, 60 years) with de novo or secondary AML underwent allogeneic HCT from related $(n=118)$ or unrelated donors ( $n=156)$ after conditioning with 2 Gy of total-body irradiation (TBI) with or without fludarabine. A calcineurin inhibitor and mycophenolate mofetil were used for postgrafting immunosuppression.

\section{Results}

With a median follow-up of 38 months in surviving patients, the estimated overall survival at 5 years was $33 \%$. The estimated 5 -year relapse/progression and nonrelapse mortality rates were $42 \%$ and $26 \%$, respectively. The cumulative incidences of grades 2, 3, and 4 acute graft-versushost disease (GVHD) were 38\%, 9\%, and 5\%, respectively. The cumulative incidence of chronic GVHD at 5 years was $44 \%$. Patients in first and second complete remission had better survival rates than patients with more advanced disease (37\% and $34 \% \vee 18 \%$, respectively). Patients with HLA-matched related or unrelated donors had similar survivals. Unfavorable cytogenetic risk status was associated with increased relapse and subsequent mortality. Chronic GVHD was associated with lower relapse risk.

\section{Conclusion}

Allogeneic HCT from related or unrelated donors after conditioning with low-dose TBI and fludarabine, relying almost exclusively on graft-versus-leukemia effects, can result in long-term remissions in older or medically infirm patients with AML.

\section{J Clin Oncol 28:2859-2867. (C) 2010 by American Society of Clinical Oncology}

\section{INTRODUCTION}

According to Surveillance, Epidemiology, and End Result statistics, the median patient age at the diagnosis of acute myeloid leukemia (AML) is 67 years. The treatment of older patients with AML remains challenging. Approximately $55 \%$ to $80 \%$ of adults with de novo AML achieve complete remissions when treated with induction therapy. ${ }^{1,2}$ These remissions, however, are rarely durable; multiple cycles of high-dose cytarabine have become the standard consolidation for patients with favorable/ intermediate cytogenetic risk younger than age 60 years. ${ }^{3}$ Patients older than age 60 years or those with comorbid conditions are usually treated with less intense regimens because of their inability to tolerate multiple cycles of high-dose chemotherapy, although a recent study by Lowenberg et $\mathrm{al}^{4}$ reported encouraging results with escalated doses of daunorubicin. In this group of patients, long-term leukemia-free survival rates are typically $10 \%$ to $15 \% .^{5,6}$ Similarly, although allogeneic hematopoietic cell transplantation (HCT) after myeloablative conditioning represents a postremission therapy option with curative potential for younger patients, ${ }^{7,8}$ concerns about treatment-related morbidity and mortality have limited its use in older patients and in those with pre-existing medical conditions. ${ }^{9}$

In recent years, the development of reducedintensity conditioning regimens has enabled older and medically infirm patients to undergo allogeneic 
HCT. These approaches rely more heavily on potent graft-versusleukemia (GVL) effects for tumor eradication. A number of studies of reduced-intensity conditioning followed by allogeneic HCT for the treatment of AML have been published, ${ }^{10-22}$ with long-term (2- to 4 -year) survival rates ranging between $28 \%$ and $54 \%$. Here, we report a multicenter experience with allogeneic HCT after nonmyeloablative conditioning with low-dose (2 Gy) total-body irradiation (TBI) with or without fludarabine in patients with AML.

\section{PATIENTS AND METHODS}

\section{Eligibility}

This analysis included all patients with de novo or secondary AML who received nonmyeloablative conditioning on multi-institutional protocols between March 4, 1998 and September 30, 2008 (Table 1). Patients were treated at 17 centers (Appendix Table A1, online only). The Fred Hutchinson Cancer Research Center (FHCRC; Seattle, WA) acted as coordinating center. Protocols and consents were approved by institutional review boards of the FHCRC and collaborating centers. All patients signed informed consent forms approved by local institutional review boards.

Patients with related or unrelated donors were eligible for nonmyeloablative conditioning if they were older than 55 or 50 years, respectively. Younger patients were included if they had otherwise prohibitive comorbid conditions. Patients in first complete remission (CR1) were only eligible if they had unfavorable cytogenetic abnormalities, had secondary AML, and/or were older than 60 years. Patients in subsequent remissions or with primary refractory leukemia were also eligible. Exclusion criteria were left ventricular ejection fraction less than $40 \%$, pulmonary carbon monoxide diffusion capacity less than $35 \%$ of predicted value, severe liver dysfunction, or serologic evidence of HIV infection.

\section{Pretransplantation Characteristics}

Complete remission (CR) was defined according to standard morphologic criteria ${ }^{23}$; morphologic CR with incomplete blood count recovery (absolute neutrophil count $<1,000 / \mu \mathrm{L}$ and/or platelet count $<100,000 / \mu \mathrm{L}$ ) was included. Cytogenetic risk was stratified per Southwest Oncology Group criteria. ${ }^{24}$ Minimal residual disease (MRD) was assessed by multiparameter flow cytometry, karyotype analysis, and fluorescence in situ hybridization when applicable, performed within 30 days before HCT. Pretransplantation comorbidities were assessed using the HCT comorbidity index (HCT-CI). ${ }^{25}$

\section{HLA Typing and Matching}

Patients and donors were tested for HLA-A, $-\mathrm{B}$, and $-\mathrm{C}$ by at least intermediate-resolution DNA typing and HLA-DRB1 and -DQB1 by highresolution techniques. ${ }^{26}$

\section{Conditioning Regimen and Postgrafting Immunosuppression}

Patients were conditioned with a single fraction of $2 \mathrm{~Gy}$ TBI at a rate of 0.07 to $0.20 \mathrm{~Gy} / \mathrm{min}$ from linear accelerators or opposing dual cobalt-60 sources on day 0 , with or without fludarabine at $30 \mathrm{mg} / \mathrm{m}^{2} / \mathrm{d}$ on days -4 through -2 before HCT. Postgrafting immunosuppression consisted of cyclosporine or tacrolimus combined with mycophenolate mofetil. ${ }^{27-30}$

\section{Post-HCT Monitoring}

Patients underwent marrow aspirations on days $28,84,180$, and 360 after HCT to assess for AML. Donor chimerism was evaluated in peripheral-blood T cells, granulocytes, and marrow cells on days 28, 84, 180, and 360 after HCT as described. ${ }^{31}$ Acute and chronic graft-versus-host disease (GVHD) were graded as described. ${ }^{32,33}$ Toxicities occurring within the first 100 days were scored using Common Terminology Criteria for Adverse Events version 3.0.

\section{Causes of Death}

In patients whose AML relapsed or progressed, relapse/progression was listed as cause of death regardless of other events. In patients with GVHD on immunosuppressive therapy who died from infections, GVHD was listed as cause of death. Infection was listed as cause of death when occurring without

\begin{tabular}{|c|c|c|}
\hline $\begin{array}{c}\text { Demographic or Clinical } \\
\text { Characteristic }\end{array}$ & $\begin{array}{l}\text { No. of Patients } \\
\quad(N=274)\end{array}$ & $\%$ \\
\hline \multicolumn{3}{|l|}{ Age, years } \\
\hline Median & \multicolumn{2}{|l|}{60} \\
\hline Range & \multicolumn{2}{|l|}{$5-74$} \\
\hline \multicolumn{3}{|l|}{ AML type } \\
\hline De novo & 188 & 69 \\
\hline Secondary & 86 & 31 \\
\hline \multicolumn{3}{|l|}{ AML stage } \\
\hline CR1 & 160 & 58 \\
\hline MRD present & 29 & \\
\hline $\mathrm{CR} 2$ & 71 & 26 \\
\hline MRD present & 13 & \\
\hline$C R>2$ & 28 & 10 \\
\hline MRD present & 11 & \\
\hline Relapse/refractory* & 15 & 6 \\
\hline \multicolumn{3}{|l|}{ Cytogenetic risk } \\
\hline Favorable & 14 & 5 \\
\hline Intermediate & 117 & 43 \\
\hline Unfavorable & 85 & 31 \\
\hline Unknown prognostic significance & 48 & 18 \\
\hline Data not available & 10 & 4 \\
\hline \multicolumn{3}{|l|}{ Time from diagnosis to $\mathrm{HCT}$, months } \\
\hline Median & \multirow{2}{*}{\multicolumn{2}{|c|}{$\begin{array}{c}8.8 \\
22-2267\end{array}$}} \\
\hline Range & & \\
\hline$<6$ & 77 & 28 \\
\hline $6-18$ & 134 & 49 \\
\hline$\geq 18$ & 63 & 23 \\
\hline \multicolumn{3}{|l|}{ No. of high-dose chemotherapy cycles } \\
\hline \multicolumn{3}{|l|}{ All patients } \\
\hline Median & \multicolumn{2}{|l|}{3} \\
\hline Range & \multicolumn{2}{|l|}{$1-16$} \\
\hline \multicolumn{3}{|l|}{ Patients in CR1 } \\
\hline Median & \multicolumn{2}{|l|}{3} \\
\hline Range & \multicolumn{2}{|l|}{$1-6$} \\
\hline \multicolumn{3}{|l|}{ Donor } \\
\hline HLA identical (related) & 117 & 43 \\
\hline HLA matched (unrelated) & 123 & 45 \\
\hline HLA mismatched & 34 & 12 \\
\hline Related & 1 & \\
\hline Unrelated & 33 & \\
\hline \multicolumn{3}{|l|}{ Conditioning } \\
\hline TBI, 2 Gy & 28 & 10 \\
\hline FLU, TBI 2 Gy & 246 & 90 \\
\hline \multicolumn{3}{|l|}{ Stem-cell source } \\
\hline Marrow & 5 & 2 \\
\hline PBSC & 269 & 98 \\
\hline Median $\mathrm{CD}_{3} 4^{+}$cell dose, $\times 10^{6} / \mathrm{kg}$ & \multicolumn{2}{|l|}{6.9} \\
\hline Median $\mathrm{CD}^{+}$cell dose, $\times 10^{8} / \mathrm{kg}$ & \multicolumn{2}{|l|}{2.9} \\
\hline GVHD prophylaxis ${ }^{\prime}$ & & \\
\hline MMF, CSP & 194 & 71 \\
\hline Tacrolimus & 80 & 29 \\
\hline Follow-up, months & & \\
\hline Median & 38 & \\
\hline Range & $6-122$ & \\
\hline Durable engraftment & & 95 \\
\hline
\end{tabular}

Abbreviations: $A M L$, acute myeloid leukemia; $C R 1$, first complete remission; MRD, minimal residual disease; CR2, second complete remission; CR, complete remission; HCT, hematopoietic cell transplantation; TBI, total-body irradiation; FLU, fludarabine; PBSC, peripheral-blood stem cells; GVHD, graftversus-host disease; MMF, mycophenolate mofetil; CSP, cyclosporine A.

*The median marrow blast count among 15 patients in relapse was $11 \%$ (range, $7 \%$ to $60 \%$ ); three of these patients had circulating blasts, and one had CNS relapse.

tCSP or tacrolimus was administered orally twice daily starting on day -3 . MMF was started on day 0 and was given to all patients twice daily initially: subsequently, the protocols were altered so that recipients of unrelated-donor allografts received MMF three times daily to reduce the risks of graft rejection and acute GVHD. 
relapse/progression or GVHD. All deaths without relapse/progression were considered nonrelapse mortality (NRM).

\section{Statistical Analysis}

Data were analyzed as of April 22, 2009. Overall survival (OS) was estimated using the Kaplan-Meier method. Cumulative incidence estimates were calculated using methods previously described. Death was treated as a competing risk in the analyses of relapse/progression and acute and chronic GVHD. Relapse/progression was treated as a competing risk when analyzing NRM. Cox regression was used for univariate and multivariate analyses of risk factors for all time-to-event end points; all $P$ values were two-sided and derived from likelihood ratio statistics.

\section{RESULTS}

\section{Patient Characteristics}

Results on 63 (23\%) of 274 patients $^{34}$ have been previously reported. Median age was 60 years (range, 5 to 74 years). One hundred eighty-eight patients had de novo AML, and 86 had secondary AML, which was therapy related in 23 patients and evolved from myelodysplastic syndrome or myeloproliferative disorder in 63 patients. Of the 274 patients, 160 were in CR1, 71 were in second CR (CR2), and 43 had more advanced leukemia. Among 264 patients with cytogenetic data available, 14 had favorable risk (three patients in CR1), 117 had intermediate risk, and 85 had unfavorable cytogenetics, whereas 48 patients had cytogenetic aberrations of unknown prognostic significance. Fifty-three patients in morphologic CR had minimal residual disease at HCT, of whom 33 (62\%) had unfavorable cytogenetics. Among patients in morphologic CR, 53 had evidence of minimal residual disease, and 197 did not; data were not available in nine patients. Median time from diagnosis to HCT was 8.8 months (range, 2.2 to 226.7 months).

\section{Transplantation Details}

One hundred seventeen patients had HLA-identical sibling donors, and 123 patients had HLA-matched unrelated donors. Thirtyfour donors were HLA mismatched at the antigen or allele level, 33 of whom were unrelated.

Twenty-eight patients received 2-Gy TBI alone, and 246 patients received 2-Gy TBI and fludarabine as additional immunosuppression. Two hundred sixty-nine patients received granulocyte colonystimulating factor-mobilized peripheral-blood mononuclear cell grafts, whereas five patients received unrelated marrow grafts. Median $\mathrm{CD}_{3}{ }^{+}$and $\mathrm{CD}^{+}$cell doses were $6.9 \times 10^{6} / \mathrm{kg}$ and $2.9 \times 10^{8} / \mathrm{kg}$ recipient weight, respectively.

\section{Engraftment}

The median neutrophil nadir occurred 15 days after HCT and was 200 cells $/ \mu \mathrm{L}$ (range, 0 to 2,000 cells $/ \mu \mathrm{L}$ ). The median duration of neutrophil counts less than 500 cells/ $\mu \mathrm{L}$ was 10 days (range, 1 to 100 days). The median platelet nadir occurred 9 days after HCT and was $30,000 / \mu \mathrm{L}$; the median duration of platelet counts less than $20,000 / \mu \mathrm{L}$ was 4 days (range, 1 to 46 days).

Four patients died before day +28 . Of the remaining $270 \mathrm{pa}-$ tients, $258(96 \%)$ had sustained engraftment. Median day +28 peripheral-blood T-cell and granulocyte donor chimerism levels (available in 260 and 187 patients, respectively) were $77.5 \%$ and 99\%, respectively. Corresponding levels on day +84 were $85 \%$ and $100 \%$, respectively. Engrafting patients received grafts containing a median of $2.9 \times 10^{8} / \mathrm{kg}$ and $7.0 \times 10^{6} / \mathrm{kg} \mathrm{CD}^{+}$and $\mathrm{CD} 34^{+}$cells, respectively.

Twelve patients (4\%) experienced graft rejection, which was primary in six patients (never $>5 \%$ donor T cells) and secondary in six patients (declines in donor T cells to $\leq 5 \%$ after initial engraftment). Two of the 12 patients (both in CR1) received 2-Gy TBI, whereas 10 patients received 2-Gy TBI and fludarabine. In patients with graft rejection, five patients had HLA-identical related grafts, six had HLAmatched unrelated grafts (three patients received marrow), and one had an HLA-A antigen-mismatched unrelated graft. Overall, rejected grafts contained a median of $2.4 \times 10^{8} / \mathrm{kg} \mathrm{CD}^{+}$cells and $4.0 \times 10^{6} / \mathrm{kg}$ $\mathrm{CD} 34^{+}$cells. In the six patients with primary graft rejection, median $\mathrm{CD}^{+}{ }^{+}$and $\mathrm{CD} 34^{+}$cell doses were $0.3 \times 10^{8} / \mathrm{kg}$ and $2.7 \times 10^{6} / \mathrm{kg}$, respectively. Although the median $\mathrm{CD}_{3} 4^{+}$cell doses were comparable between engrafting and rejecting patients, the $\mathrm{CD}^{+}$cell dose was approximately a log lower in patients with primary graft rejection than in patients with durable engraftment or secondary graft rejection.

Five patients who experienced graft rejection underwent second allogeneic HCT, and four of these patients died (relapse, $n=1 ; N R M$, $\mathrm{n}=3$ ). Seven patients did not undergo second HCT; one is alive with MDS, and six died of relapse, despite donor lymphocyte infusions in two patients.

\section{GVHD and Toxicity}

Acute GVHD developed at a median of 42 days after HCT. The cumulative incidences of grade 2, 3, and 4 acute GVHD were $38 \%, 9 \%$, and $5 \%$, respectively (Figs $1 \mathrm{~A}$ and $1 \mathrm{~B}$ ). The cumulative incidence of grade 2 acute GVHD was less with HLA-identical related donors than with HLA-matched unrelated donors (28\% v 43\%, respectively), whereas the incidences of grade 3-4 acute GVHD were comparable ( $12 \%$ each). The rates of both grade 2 and grade $3-4$ acute GVHD were higher in patients with HLA-mismatched unrelated grafts (50\% and 24\%, respectively). Chronic GVHD developed in $43 \%$ of patients (Fig 1C), with similar cumulative incidences among all three patient groups $(44 \%, 41 \%$, and $41 \%$ in HLA-identical related, HLA-matched unrelated, and HLA-mismatched donors, respectively). Grade 4 nonhematologic toxicities were uncommon and included mainly pulmonary, cardiovascular, and hepatic toxicities (15, 11, and 10 events, respectively).

\section{Relapse, Progression, and Relapse-Related Mortality}

The median follow-up time of surviving patients was 38 months (range, 6 to 122 months). Of the 274 patients, 113 developed relapse/ progression, which was fatal in 106 . The overall 5-year probability of relapse/progression was $42 \%$. Median time to relapse/progression was 84 days. Patients with favorable/intermediate and unclassified cytogenetics had lower 5-year relapse/progression rates than patients with unfavorable cytogenetics $(36 \%, 32 \%$, and 55\%, respectively; Fig $2 \mathrm{~B})$. The 5-year probabilities of relapse/disease progression for patients in CR1, CR2, and with advanced/refractory AML were $39 \%, 41 \%$, and 52\%, respectively (Figs 3A, 3B, and 3C). Although HLA-mismatched unrelated recipients seemed to have less 5-year relapse/progression than HLA-matched related or unrelated recipients (25\% $v 47 \%$ and $42 \%$, respectively), these differences did not reach statistical significance. 


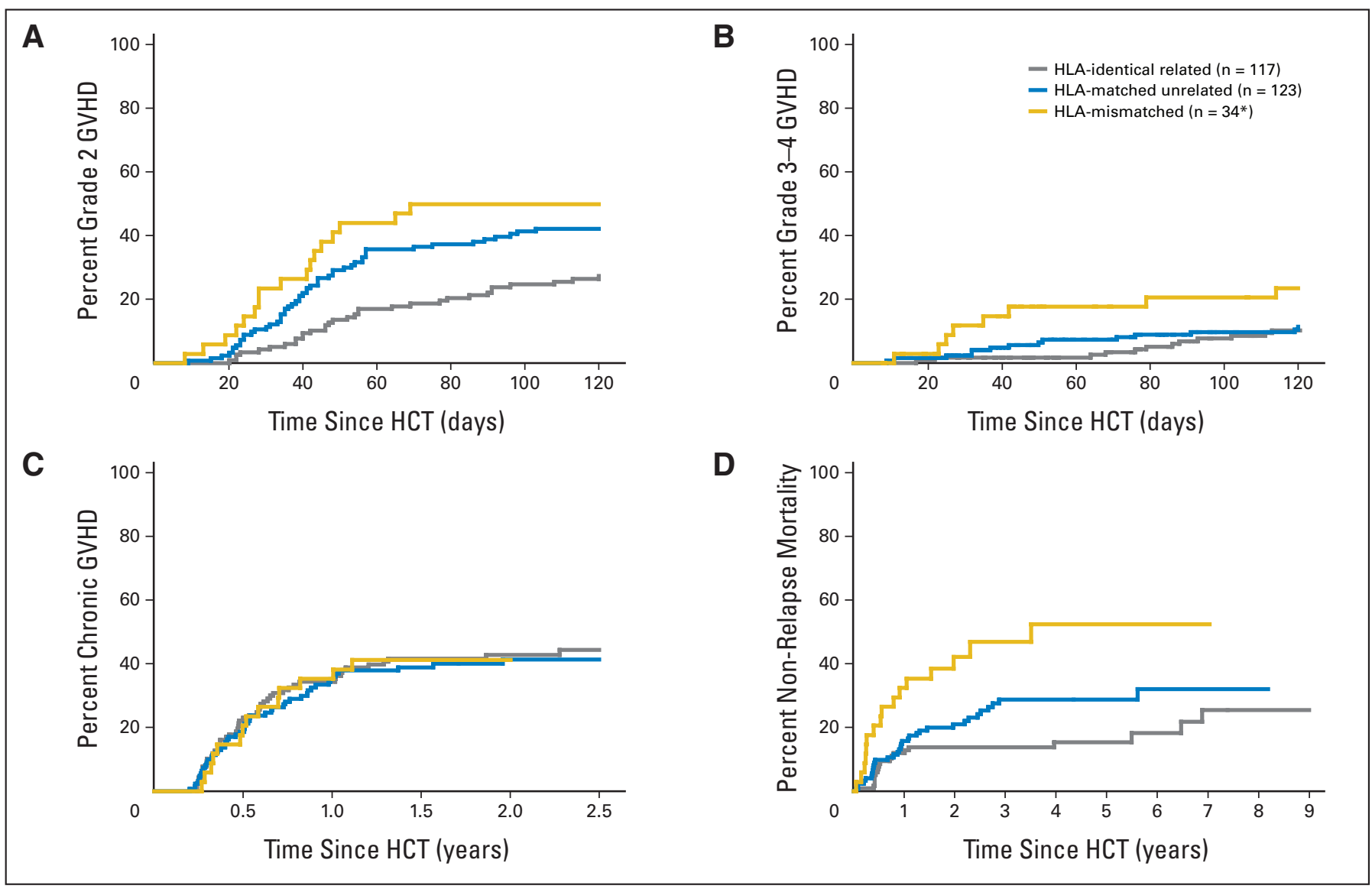

Fig 1. Cumulative incidences of (A) grade 2 acute graft-versus-host disease (GVHD), (B) grade 3 or 4 acute GVHD, and (C) chronic GVHD. (D) Estimated probability of nonrelapse mortality stratified by donor type. $\left(^{*}\right)$ Thirty-three of the HLA-mismatched donors were unrelated. HCT, hematopoietic cell transplantation.

Patients with unfavorable cytogenetics, patients with minimal residual disease, patients undergoing HCT within 6 months of diagnosis, and patients with incomplete peripheral-blood cell count recoveries before HCT had higher risks of relapse/progression in univariate analysis (Table 2). Factors without statistically significant impact on relapse/progression were age, AML stage, etiology (de novo $v$ second- ary), and donor type (HLA-identical related $v$ HLA-matched unrelated $v$ HLA-mismatched unrelated). In a multivariate model, the impacts of MRD and peripheral-blood cell count recovery lost statistical significance, whereas cytogenetic risk status and time between diagnosis and HCT remained significantly associated with relapse/ progression and overall mortality.

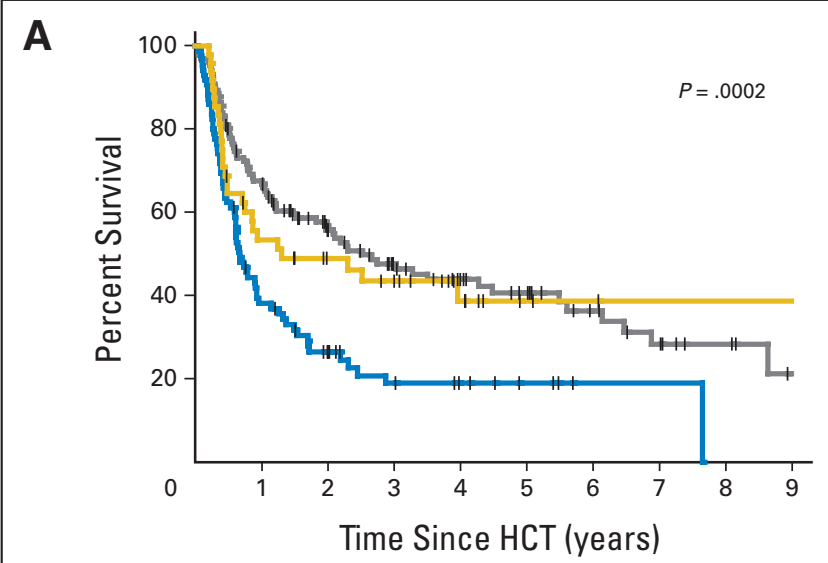

B

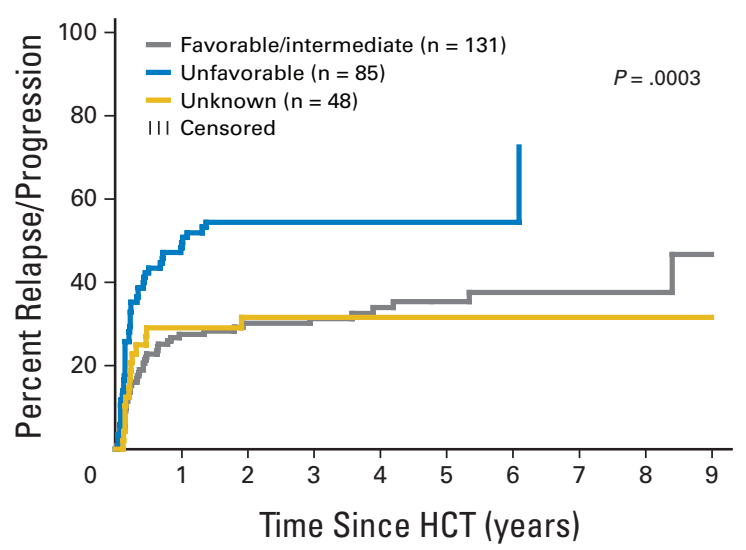

Fig 2. (A) Overall survival and (B) relapse/progression stratified by cytogenetic risk before hematopoietic cell transplantation (HCT). Total number of patients was 264 because cytogenetic data were not available in 10 patients. 


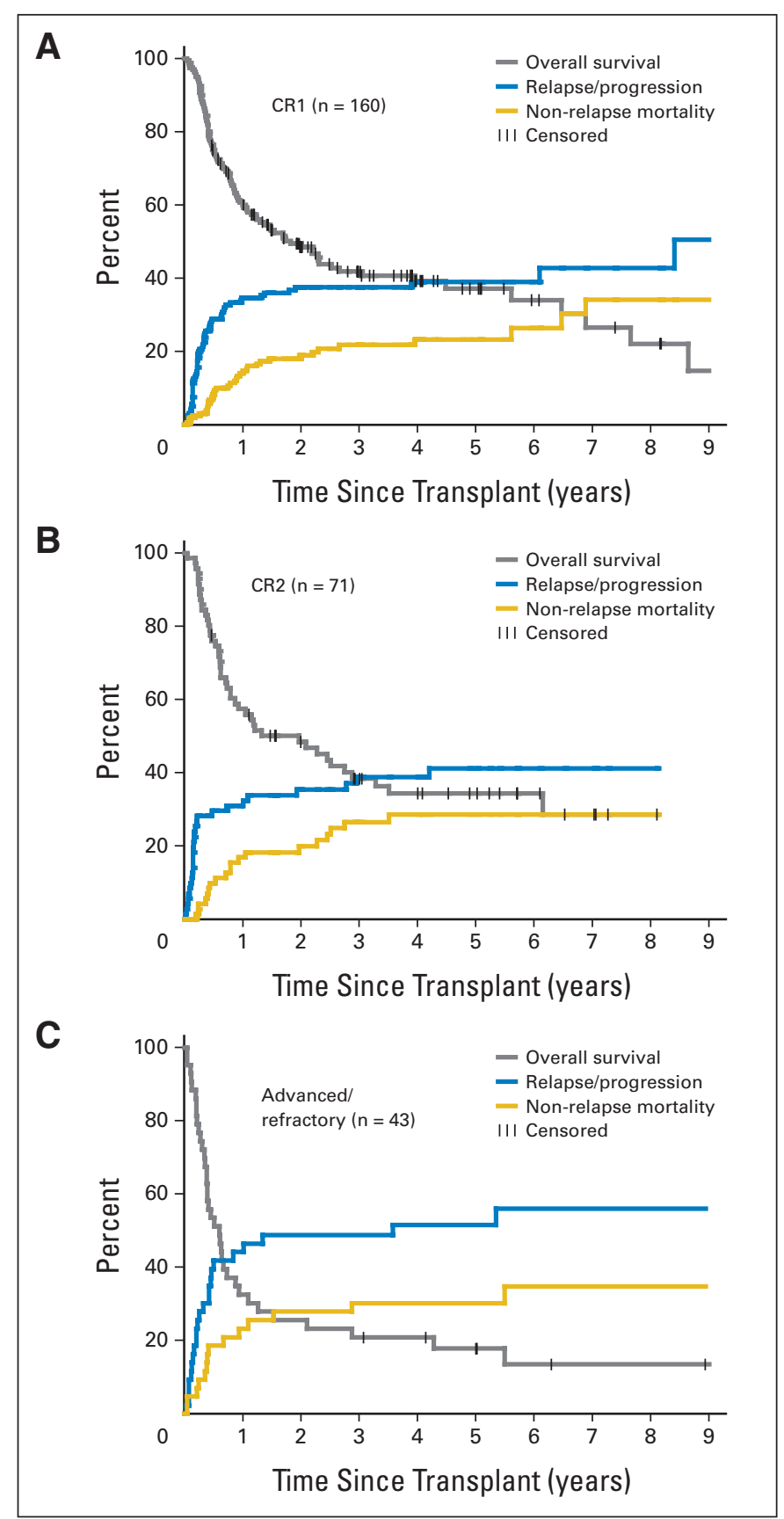

Fig 3. Overall survival, relapse/progression rate, and nonrelapse mortality of patients with acute myeloid leukemia in first complete remission (CR1), in second complete remission (CR2), and with more advanced/refractory disease.

More advanced AML was associated with greater risks of relapse and mortality. The presence of MRD was not identified as an independent risk factor for relapse/progression, possibly because of its close association with unfavorable cytogenetics; 33 (62\%) of 53 patients with MRD had unfavorable cytogenetics.

Similarly, among patients in CR1, the absence of pre-HCT peripheral-blood cell count recovery, unfavorable cytogenetics, and MRD were associated with increased risk of relapse/progression in univariate analysis (Table 2; Appendix Figs A1A and A1B, online only); cytogenetics and peripheral-blood cell count recovery re- mained significantly associated with relapse/progression in a multivariate model. Cytogenetics was the single factor influencing overall mortality in a multivariate model for patients in CR1 (Appendix Table A2, online only).

In a time-dependent analysis, the presence of acute GVHD (grade $\geq 2$ ) did not affect relapse/progression. In contrast, chronic GVHD was associated with a significant decrease in relapse/progression (Table 3).

\section{Survival and Causes of Death}

At the time of last follow-up, 99 of 274 patients were alive. The 5 -year rates of OS and disease-free survival were $33 \%$ and $32 \%$, respectively. Patients in CR1 and CR2 had better 5-year OS than patients with more advanced AML (37\% and 34\%, respectively, $v 18 \%$; $P=.008$; Fig 3). Patients with HLA-mismatched unrelated donors had slightly worse 5-year OS than patients with HLA-matched related or unrelated donors, which was not statistically significant $(22 \% \mathrm{v}$ $37 \%$ and $33 \%$, respectively; $P=.37$ ). Patients with HLA-identical related donors had lower NRM than patients with HLA-matched or HLA-mismatched unrelated donors (18\% v 29\% and 52\%, respectively; $P=.005$; Fig 1D). In addition, patients with favorable/intermediate and unclassified cytogenetics had better OS than patients with unfavorable cytogenetics ( $41 \%$ and 39\%, respectively, $v 19 \% ; P<.001$; Fig 2A). The leading cause of death was relapse (106 patients).

\section{Risk Factors for NRM}

The 100-day, 1-year, and 5-year NRM rates were 4\%, 16\%, and $26 \%$, respectively. The majority of NRM was caused by GVHD or a combination of GVHD and infections (48 patients; Appendix Table A3, online only). Patients with HLA-matched and HLA-mismatched unrelated donors had increased risk of NRM and mortality in a multivariate analysis (Appendix Table A2). Age at HCT, the etiology of AML, pre-HCT CBC recovery, and HCT-CI scores did not have statistically significant impacts on NRM. Although there was a tendency of increased NRM for patients with HCT-CI scores of $\geq 4$, this remained a trend $(P=.08$; Appendix Table A2).

\section{DISCUSSION}

Patients with AML older than 60 years of age have a poor prognosis with conventional chemotherapy and are usually not candidates for allogeneic HCT with high-dose conditioning regimens. Allogeneic HCT after a variety of reduced-intensity conditioning regimens has been introduced in recent years, with encouraging results reported in patients with AML. ${ }^{11-15,17,21}$ Many studies used fludarabine-based conditioning regimens with addition of an alkylating agent and, in some cases, in vivo T-cell depletion with antithymocyte globulin or alemtuzumab. ${ }^{10,12-14}$

At the FHCRC, a low-dose TBI-based conditioning regimen has been developed based on studies in a canine HCT model. ${ }^{35-39}$ The regimen consists of 2-Gy TBI with or without fludarabine ${ }^{40}$ and postgrafting immunosuppression with a calcineurin inhibitor and mycophenolate mofetil. The regimen has relied almost entirely on GVL effects for treating AML.

The engraftment rate in this study was $96 \%$. The median donor $\mathrm{CD}^{+}$cell dose was almost a log lower in patients with primary graft 


\begin{tabular}{|c|c|c|c|c|c|c|c|}
\hline \multirow[b]{2}{*}{ Variable } & \multirow[b]{2}{*}{$\begin{array}{l}\text { No. of } \\
\text { Patients }\end{array}$} & \multicolumn{3}{|c|}{ Univariate Analysis } & \multicolumn{3}{|c|}{ Multivariate Analysis* } \\
\hline & & $\begin{array}{l}\text { HR for Relapse/ } \\
\text { Progression }\end{array}$ & $95 \% \mathrm{Cl}$ & $P$ & $\begin{array}{l}\text { HR for Relapse/ } \\
\text { Progression }\end{array}$ & $95 \% \mathrm{Cl}$ & $P$ \\
\hline \multicolumn{8}{|l|}{ All patients } \\
\hline \multicolumn{8}{|l|}{ Age at $\mathrm{HCT}$, years } \\
\hline$<60$ & 139 & 1.0 & & .66 & 1.0 & & .97 \\
\hline$\geq 60$ & 135 & 0.92 & 0.6 to 1.3 & & 1.01 & 0.6 to 1.6 & \\
\hline AML etiology & & & & & & & .84 \\
\hline De novo & 188 & 1.0 & & .09 & 1.0 & & \\
\hline Secondary & 86 & 1.40 & 1.0 to 2.1 & & 1.06 & 0.6 to 1.8 & \\
\hline \multicolumn{8}{|l|}{ AML stage } \\
\hline CR1 & 160 & 1.0 & & .14 & 1.0 & & $<.001$ \\
\hline CR2 & 71 & 1.06 & 0.7 to 1.7 & & 2.51 & 1.4 to 4.6 & \\
\hline Advanced/refractory & 43 & 1.65 & 1.0 to 2.7 & & 5.89 & 3.0 to 12 & \\
\hline \multicolumn{8}{|l|}{ MRD at HCT +} \\
\hline No & 197 & 1.0 & & .02 & 1.0 & & .83 \\
\hline Yes & 53 & 1.76 & 1.1 to 2.8 & & 1.07 & 0.6 to 1.9 & \\
\hline \multicolumn{8}{|l|}{ Cytogenetic risk } \\
\hline Favorable/intermediate & 131 & 1.0 & & $<.001$ & 1.0 & & .001 \\
\hline Unfavorable & 85 & 2.27 & 1.5 to 3.4 & & 2.71 & 1.6 to 4.6 & \\
\hline Unknown prognostic significance & 48 & 0.98 & 0.5 to 1.8 & & 1.18 & 0.6 to 2.3 & \\
\hline \multicolumn{8}{|l|}{ Months from diagnosis to $\mathrm{HCT}$} \\
\hline$<6$ & 77 & 1.0 & & $<.001$ & 1.0 & & $<.001$ \\
\hline $6-18$ & 134 & 0.88 & 0.6 to 1.3 & & 0.81 & 0.5 to 1.4 & \\
\hline$\geq 18$ & 63 & 0.34 & 0.2 to 0.6 & & 0.15 & 0.1 to 0.4 & \\
\hline \multicolumn{8}{|l|}{ Blood count recovery at $\mathrm{HCT}$} \\
\hline Yes & 141 & 1.0 & & .05 & 1.0 & & .06 \\
\hline No & 112 & 1.49 & 1.0 to 2.2 & & 1.55 & 1.0 to 2.5 & \\
\hline \multicolumn{8}{|l|}{ Donor } \\
\hline HLA-identical sibling & 117 & 1.0 & & .21 & 1.0 & & .39 \\
\hline HLA-matched unrelated donor & 134 & 0.94 & 0.6 to 1.4 & & 1.03 & 0.6 to 1.7 & \\
\hline HLA-mismatched unrelated donor & 34 & 0.54 & 0.3 to 1.1 & & 0.59 & 0.2 to 1.5 & \\
\hline \multicolumn{8}{|l|}{ Patients in CR1 } \\
\hline \multicolumn{8}{|l|}{ Age at HCT, years } \\
\hline$<60$ & 73 & 1.0 & & .17 & 1.0 & & .42 \\
\hline$\geq 60$ & 87 & 0.71 & 0.4 to 1.2 & & 0.78 & 0.4 to 1.4 & \\
\hline \multicolumn{8}{|l|}{ AML etiology } \\
\hline De novo & 102 & 1.0 & & .26 & 1.0 & & .50 \\
\hline Secondary & 58 & 1.34 & 0.8 to 2.2 & & 0.79 & 0.4 to 1.6 & \\
\hline \multicolumn{8}{|l|}{ MRD at HCT } \\
\hline No & 125 & 1.0 & & .02 & 1.0 & & .48 \\
\hline Yes & 29 & 2.10 & 1.2 to 3.8 & & 1.33 & 0.6 to 2.9 & \\
\hline \multicolumn{8}{|l|}{ Cytogenetic risk } \\
\hline Favorable/intermediate & 71 & 1.0 & & .002 & 1.0 & & .01 \\
\hline Unfavorable & 50 & 2.33 & 1.3 to 4.1 & & 2.60 & 1.2 to 5.6 & \\
\hline Unknown prognostic significance & 33 & 0.74 & 0.3 to 1.6 & & 0.81 & 0.3 to 2.0 & \\
\hline Months from diagnosis to $\mathrm{HCT}$ & & & & & & & \\
\hline$<6$ & 72 & 1.0 & & .07 & 1.0 & & .91 \\
\hline$\geq 6$ & 88 & 0.60 & 0.3 to 1.0 & & 0.96 & 0.5 to 1.9 & \\
\hline Blood count recovery at $\mathrm{HCT}$ & & & & & & & \\
\hline Yes & 91 & 1.0 & & .03 & 1.0 & & .02 \\
\hline No & 55 & 1.83 & 1.1 to 3.2 & & 2.24 & 1.1 to 4.4 & \\
\hline Donor & & & & & & & \\
\hline HLA-identical sibling & 75 & 1.0 & & .62 & 1.0 & & .35 \\
\hline HLA-matched unrelated donor & 69 & 0.90 & 0.5 to 1.5 & & 1.19 & 0.6 to 2.4 & \\
\hline HLA-mismatched unrelated donor & 16 & 0.62 & 0.2 to 1.8 & & 0.52 & 0.1 to 2.0 & \\
\hline $\begin{array}{l}\text { NOTE. The No. of prior high dose-chem } \\
\text { significant association with the risk of re } \\
\text { Abbreviations: HR, hazard ratio; HCT, } \\
\text { remission; MRD, minimal residual disea } \\
\text { "Data on all variables were available for } \\
\text { were available for } 130 \text { patients. } \\
\text { †Among } 250 \text { patients in morphologic }\end{array}$ & $\begin{array}{l}\text { rapy treatm } \\
\text { e/progressi } \\
\text { atopoietic c } \\
\text { patients un } \\
\text { lete remiss }\end{array}$ & $\begin{array}{l}\text { cycles and HCT Cor } \\
\text { ransplantation; AM } \\
\text { going HCT with non } \\
\text { in univariate analysi }\end{array}$ & $\begin{array}{l}\text { bidity Index s } \\
\text { cute myeloid } \\
\text { mong } 215 \mathrm{p}\end{array}$ & $\begin{array}{l}\text { es were al } \\
\text { Ikemia; CF } \\
\text { tioning. In } \\
\text { tts in mor }\end{array}$ & $\begin{array}{l}\text { ncluded in the mode } \\
\text { irst complete remis } \\
\text { subgroup of patient } \\
\text { ogic complete remi }\end{array}$ & $\begin{array}{l}\text { t did not hav } \\
\text { CR2, seco } \\
\text { CR1, data on } \\
\text { in multivari }\end{array}$ & $\begin{array}{l}\text { atistically } \\
\text { complete } \\
\text { variables } \\
\text { analysis. }\end{array}$ \\
\hline
\end{tabular}




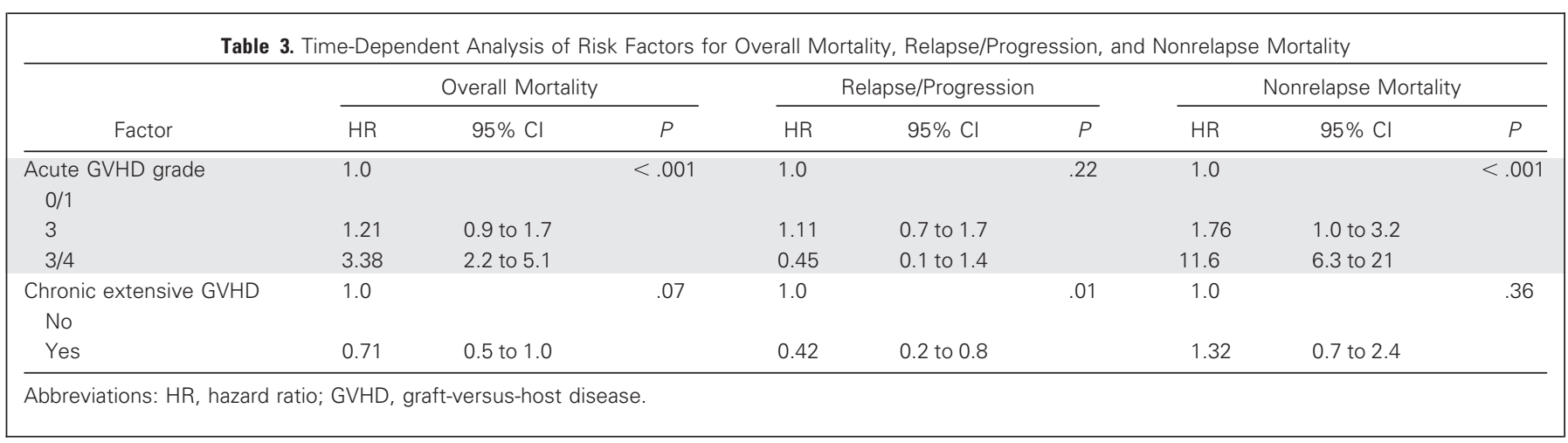

rejection than in patients with durable engraftment, emphasizing the role $\mathrm{T}$ cells play in engraftment. The degree of HLA disparity did not impact the rate of engraftment in this cohort.

Allogeneic HCT after conditioning with 2-Gy TBI with or without fludarabine was well tolerated in this cohort of older and/or medically infirm patients and resulted in improved OS rates in all disease stages. With a median follow-up time of 38 months, patients in CR1 had an estimated 5-year OS rate of 37\%, which represents an improvement when compared with historical data using chemotherapy only (reported 3 -year survival rates of $2 \%$ to $15 \%{ }^{41}$ ), especially when considering that current patients in CR1 were either older than 60 years or had unfavorable cytogenetics and/or secondary AML. The 5 -year OS in patients in CR2 and with more advanced AML (34\% and $18 \%$, respectively) was also better than expected than with chemotherapy alone ( $11 \%$ at 5 years for 667 patients in first relapse in a study by Breems et $\mathrm{al}^{42}$ ).

Patients in the current study were slightly older compared with patients in other reports of allogeneic HCT after reduced-intensity conditioning, (median age, 60 years $v 58,{ }^{11} 56,{ }^{15} 53,{ }^{21}$ and 52 years, ${ }^{13}$ respectively); however, the current 5-year NRM rate of $26 \%$ was comparable to the rates reported by others, which ranged from $20 \%$ to $53 \%$ at 2 and 4 years. ${ }^{10,14,21}$ The leading cause of NRM in current patients was GVHD, resulting in death in $18 \%$ of patients; however, GVHD rates in our patients (grade 3-4 acute GVHD, 14\%; chronic GVHD, 44\%) were similar to the rates reported in a recent Center for International Blood and Marrow Transplant Research study of younger patients undergoing high-dose conditioning before allogeneic HCT. ${ }^{43}$ Infections in the absence of GVHD caused the deaths of $2 \%$ of our patients, suggesting a more rapid immune reconstitution in this cohort when compared with reduced-intensity conditioning regimens incorporating in vivo $\mathrm{T}$-cell depletion, with reported infectionrelated mortality rates of $6 \%$ to $12 \% .{ }^{10,14}$

The leading cause of treatment failure in previous studies of reduced-intensity conditioning regimens in patients with AML was relapse/progression, with 2- to 4 -year relapse rates of $32 \%$ to $61 \%,{ }^{11,13,15,17}$ although a single-institution report by Mohty et $\mathrm{al}^{12}$ described a $12 \%$ relapse rate at 4 years in 25 patients in CR1 undergoing reduced-intensity conditioning. Similarly, the leading cause of mortality in our study was relapse, with a 5-year estimated overall relapse/progression rate of $42 \%$.

The current study showed higher relapse rates in patients with advanced disease, patients with unfavorable cytogenetics, and patients who underwent HCT within 6 months of diagnosis of AML. Further- more, there was a suggestion of higher relapse/progression rates in patients with poor blood cell count recovery before HCT, which either represented impaired marrow function as a result of leukemia not detected by other methods, underlying myelodysplastic syndrome, or decreased hematopoietic reserve as a result of chemotherapy damage. Overall, our findings suggested that larger leukemia burden and perhaps faster proliferation rates associated with unfavorable cytogenetics enabled leukemic cells to outgrow GVL effects, a suggestion that was supported by the observation that more than half of the relapses occurred within 100 days of HCT. A previous report from our institution, investigating various hematologic malignancies at different disease stages, showed that graft-versus-tumor effects were most powerful in patients with relatively low tumor burden and more indolent tumors like chronic lymphocytic leukemia. ${ }^{44}$

Given the above observations regarding leukemia burden, it was surprising that MRD, while associated with higher risk of relapse in a univariate analysis, was no longer an independent risk factor when the multivariate analysis was adjusted to include cytogenetic risk. Most likely this was a result of the fact that a majority of patients (62\%) with MRD had unfavorable cytogenetics, suggesting a codependency of these two variables. Furthermore, our observations are limited by relatively small patient numbers and variations in the techniques of disease assessment over time and among participating sites. Refinements in flow cytometry and molecular methods to assess leukemia burden and prognosis of AML (eg, NPM1 mutation analysis reported by Schnittger et $\mathrm{al}^{45}$ ) will be important in the design of future studies.

In conclusion, allogeneic HCT from related or unrelated donors after nonmyeloablative conditioning resulted in long-term diseasefree survival in patients with AML who were not considered candidates for myeloablative conditioning because of age or comorbid conditions. Best outcomes were observed in patients in CR1 or CR2 who had favorable/intermediate cytogenetic risks. New strategies will be required in patients with advanced AML and in patients with unfavorable cytogenetics with the aim of increasing GVL effects and thereby reducing relapse, which clearly has been the major cause of treatment failure.

\section{AUTHORS' DISCLOSURES OF POTENTIAL CONFLICTS} OF INTEREST

The author(s) indicated no potential conflicts of interest. 


\section{AUTHOR CONTRIBUTIONS}

Conception and design: Rainer Storb, Barry E. Storer,

Brenda M. Sandmaier

Financial support: Rainer Storb, Frederick R. Appelbaum

Administrative support: Rainer Storb, Frederick R. Appelbaum,

Brenda M. Sandmaier

Provision of study materials or patients: Rainer Storb, Thomas R.

Chauncey, Thoralf Lange, Judith A. Shizuru, Amelia A. Langston,

Michael A. Pulsipher, Richard T. Maziarz, Benedetto Bruno, Finn B.

Petersen, Michael B. Maris, Edward Agura, Andrew Yeager, Wolfgang

Bethge, Firoozeh Sahebi, Frederick R. Appelbaum, David G. Maloney,

Brenda M. Sandmaier

Collection and assembly of data: Boglarka Gyurkocza, Rainer Storb, Thoralf Lange, Judith A. Shizuru, Amelia A. Langston, Finn B.
Petersen, Michael B. Maris, Edward Agura, Andrew Yeager,

Wolfgang Bethge, Firoozeh Sahebi, David G. Maloney,

Brenda M. Sandmaier

Data analysis and interpretation: Boglarka Gyurkocza, Rainer Storb, Barry E. Storer, Thomas R. Chauncey, Christopher N. Bredeson, Richard T. Maziarz, Edward Agura, Brenda M. Sandmaier

Manuscript writing: Boglarka Gyurkocza, Rainer Storb, Barry E. Storer, Michael A. Pulsipher, Christopher N. Bredeson, Richard T. Maziarz, Wolfgang Bethge, Brenda M. Sandmaier

Final approval of manuscript: Boglarka Gyurkocza, Rainer Storb, Barry E. Storer, Thomas R. Chauncey, Thoralf Lange, Judith A. Shizuru, Amelia A. Langston, Michael A. Pulsipher, Christopher N. Bredeson, Richard T. Maziarz, Benedetto Bruno, Finn B. Petersen, Michael B. Maris, Edward Agura, Andrew Yeager, Wolfgang Bethge, Firoozeh Sahebi, Frederick R. Appelbaum, David G. Maloney, Brenda M. Sandmaier

\section{REFERENCES}

1. Berman E, Heller G, Santorsa J, et al: Results of a randomized trial comparing idarubicin and cytosine arabinoside with daunorubicin and cytosine arabinoside in adult patients with newly diagnosed acute myelogenous leukemia. Blood 77:1666-1674, 1991

2. Bishop JF, Matthews JP, Young GA, et al: A randomized study of high-dose cytarabine in induction in acute myeloid leukemia. Blood 87:1710-1717, 1996

3. Mayer RJ, Davis RB, Schiffer CA, et al: Intensive postremission chemotherapy in adults with acute myeloid leukemia. N Engl J Med 331:896-903, 1994

4. Löwenberg B, Ossenkoppele GJ, van Putten W, et al: High-dose daunorubicin in older patients with acute myeloid leukemia. N Engl J Med 361: 1235-1248, 2009

5. Godwin JE, Kopecky KJ, Head DR, et al: A double-blind placebo-controlled trial of granulocyte colony-stimulating factor in elderly patients with previously untreated acute myeloid leukemia: A Southwest Oncology Group study (9031). Blood 91:3607-3615, 1998

6. Anderson JE, Kopecky KJ, Willman CL, et al: Outcome after induction chemotherapy for older patients with acute myeloid leukemia is not improved with mitoxantrone and etoposide compared to cytarabine and daunorubicin: A Southwest Oncology Group study. Blood 100:3869-3876, 2002

7. Krauter J, Heil G, Hoelzer D, et al: Role of consolidation therapy in the treatment of patients up to 60 years with high risk AML. Blood 106:54a, 2005 (abstr 172)

8. Gale RP, Horowitz MM, Rees JK, et al: Chemotherapy versus transplants for acute myelogenous leukemia in second remission. Leukemia 10:13-19, 1996

9. Wallen $\mathrm{H}$, Gooley TA, Deeg HJ, et al: Ablative allogeneic hematopoietic cell transplantation in adults 60 years of age and older. J Clin Oncol 23:3439-3446, 2005

10. Sayer HG, Kröger M, Beyer J, et al: Reduced intensity conditioning for allogeneic hematopoietic stem cell transplantation in patients with acute myeloid leukemia: Disease status by marrow blasts is the strongest prognostic factor. Bone Marrow Transplant 31:1089-1095, 2003

11. de Lima M, Anagnostopoulos A, Munsell M, et al: Nonablative versus reduced-intensity conditioning regimens in the treatment of acute myeloid leukemia and high-risk myelodysplastic syndrome:
Dose is relevant for long-term disease control after allogeneic hematopoietic stem cell transplantation. Blood 104:865-872, 2004

12. Mohty $M$, de Lavallade $H$, Ladaique $P$, et al: The role of reduced intensity conditioning allogeneic stem cell transplantation in patients with acute myeloid leukemia: A donor vs no donor comparison. Leukemia 19:916-920, 2005

13. Tauro S, Craddock $C$, Peggs $K$, et al: Allogeneic stem-cell transplantation using a reducedintensity conditioning regimen has the capacity to produce durable remissions and long-term diseasefree survival in patients with high-risk acute myeloid leukemia and myelodysplasia. J Clin Oncol 23:93879393, 2005

14. van Besien $K$, Artz A, Smith $S$, et al: Fludarabine, melphalan, and alemtuzumab conditioning in adults with standard-risk advanced acute myeloid leukemia and myelodysplastic syndrome. J Clin Oncol 23:5728-5738, 2005

15. Alyea EP, Kim HT, Ho V, et al: Impact of conditioning regimen intensity on outcome of allogeneic hematopoietic cell transplantation for advanced acute myelogenous leukemia and myelodysplastic syndrome. Biol Blood Marrow Transplant 12:10471055, 2006

16. Gorin NC, Labopin M, Boiron JM, et al: Results of genoidentical hemopoietic stem cell transplantation with reduced intensity conditioning for acute myelocytic leukemia: Higher doses of stem cells infused benefit patients receiving transplants in second remission or beyond-The Acute Leukemia Working Party of the European Cooperative Group for Blood and Marrow Transplantation. J Clin Oncol 24:3959-3966, 2006

17. Shimoni A, Hardan I, Shem-Tov N, et al: Allogeneic hematopoietic stem-cell transplantation in $\mathrm{AML}$ and $\mathrm{MDS}$ using myeloablative versus reduced-intensity conditioning: The role of dose intensity. Leukemia 20:322-328, 2006

18. McClune B, Weisdorf DJ, DiPersio JF, et al: Non-myeloablative hematopoietic stem cell transplantation in older patients with $\mathrm{AML}$ and MDS: Results from the Center for International Blood and Marrow Transplant Research (CIBMTR). Blood 112: 135, 2008 (abstr 346)

19. Mohty M, Labopin M, Milpied N-J, et al: Impact of cytogenetics risk on outcome after reduced intensity conditioning (RIC) allogeneic stem cell transplantation (allo-SCT) from an HLA identical sibling for patients with acute myeloid leukemia $(A M L)$ in first complete remission (CR1). Blood 112: 134-135, 2008 (abstr 345)

20. Pfeifer $T$, Schleuning $M$, Eder $M$, et al: Improved outcome for patients with acute myeloid leukemia (AML) and myelodysplastic syndrome (MDS) with poor risk cytogenetics: Result from an analysis on 172 patients receiving FLAMSA-RIC conditioning for allogeneic stem cell transplantation (SCT). Blood 112:688, 2008 (abstr 1971)

21. Valcárcel $D$, Martino $R$, Caballero $D$, et al: Sustained remissions of high-risk acute myeloid leukemia and myelodysplastic syndrome after reduced-intensity conditioning allogeneic hematopoietic transplantation: Chronic graft-versus-host disease is the strongest factor improving survival. $\mathrm{J}$ Clin Oncol 26:577-584, 2008

22. Ringdén $\mathrm{O}$, Labopin $\mathrm{M}$, Ehninger $\mathrm{G}$, et al: Reduced intensity conditioning compared with myeloablative conditioning using unrelated donor transplants in patients with acute myeloid leukemia. $\mathrm{J}$ Clin Oncol 27:4570-4577, 2009

23. Cheson BD, Bennett JM, Kopecky KJ, et al: Revised recommendations of the International Working Group for Diagnosis, Standardization of Response Criteria, Treatment Outcomes, and Reporting Standards for Therapeutic Trials in Acute Myeloid Leukemia. J Clin Oncol 21:4642-4649, 2003

24. Slovak ML, Kopecky KJ, Cassileth PA, et al: Karyotypic analysis predicts outcome of preremission and postremission therapy in adult acute myeloid leukemia: A Southwest Oncology Group/ Eastern Cooperative Oncology Group study. Blood 96:4075-4083, 2000

25. Sorror ML, Maris MB, Storb R, et al: Hematopoietic cell transplantation (HCT)-specific comorbidity index: A new tool for risk assessment before allogeneic HCT. Blood 106:2912-2919, 2005

26. Petersdorf EW, Gooley TA, Anasetti $C$, et al: Optimizing outcome after unrelated marrow transplantation by comprehensive matching of HLA class | and || alleles in the donor and recipient. Blood 92:3515-3520, 1998

27. Maris MB, Niederwieser D, Sandmaier BM, et al: HLA-matched unrelated donor hematopoietic cell transplantation after nonmyeloablative conditioning for patients with hematologic malignancies. Blood 102:2021-2030, 2003

28. Kerbauy FR, Storb R, Hegenbart $U$, et al: Hematopoietic cell transplantation from HLAidentical sibling donors after low-dose radiationbased conditioning for treatment of CML. Leukemia 19:990-997, 2005

29. Maloney DG, Molina AJ, Sahebi $F$, et al: Allografting with nonmyeloablative conditioning following cytoreductive autografts for the treatment of patients with multiple myeloma. Blood 102:34473454, 2003 
30. Baron F, Maris MB, Storer BE, et al: HLAmatched unrelated donor hematopoietic cell transplantation after nonmyeloablative conditioning for patients with chronic myeloid leukemia. Biol Blood Marrow Transplant 11:272-279, 2005

31. Sandmaier BM, Maris M, Maloney DG, et al: Low-dose total body irradiation (TBI) conditioning for hematopoietic cell transplants (HCT) from HLAmatched related (MRD) and unrelated (URD) donors for patients with hematologic malignancies: A fiveyear experience. Blood 102:78a-79a, 2003 labstr 264)

32. Przepiorka D, Weisdorf D, Martin $P$, et al: 1994 Consensus conference on acute GVHD grading. Bone Marrow Transplant 15:825-828, 1995

33. Filipovich $A H$, Weisdorf $D$, Pavletic $S$, et al: National Institutes of Health consensus development project on criteria for clinical trials in chronic graft-versus-host disease: I. Diagnosis and Staging Working Group report. Biol Blood Marrow Transplant 11:945-956, 2005

34. Hegenbart $U$, Niederwieser D, Sandmaier BM, et al: Treatment for acute myelogenous leukemia by low-dose, total-body, irradiation-based conditioning and hematopoietic cell transplantation from related and unrelated donors. J Clin Oncol 24:444453,2006
35. Storb R, Raff RF, Appelbaum FR, et al: What radiation dose for DLA-identical canine marrow grafts? Blood 72:1300-1304, 1988

36. Storb R, Raff RF, Appelbaum FR, et al: DLAidentical bone marrow grafts after low-dose total body irradiation: The effect of canine recombinant hematopoietic growth factors. Blood 84:3558-3566, 1994

37. Yu C, Storb R, Mathey B, et al: DLA-identical bone marrow grafts after low-dose total body irradiation: Effects of high-dose corticosteroids and cyclosporine on engraftment. Blood 86:4376-4381, 1995

38. Storb R, Yu C, Wagner JL, et al: Stable mixed hematopoietic chimerism in DLA-identical littermate dogs given sublethal total body irradiation before and pharmacological immunosuppression after marrow transplantation. Blood 89:3048-3054, 1997

39. Hogan WJ, Little MT, Zellmer E, et al: Postgrafting immunosuppression with sirolimus and cyclosporine facilitates stable mixed hematopoietic chimerism in dogs given sublethal total body irradiation before marrow transplantation from DLAidentical littermates. Biol Blood Marrow Transplant 9:489-495, 2003

40. Niederwieser D, Maris M, Shizuru JA, et al: Low-dose total body irradiation (TBI) and fludarabine followed by hematopoietic cell transplantation (HCT) from HLA-matched or mismatched unrelated donors and postgrafting immunosuppression with cyclosporine and mycophenolate mofetil (MMF) can induce durable complete chimerism and sustained remissions in patients with hematological diseases. Blood 101:1620-1629, 2003

41. Wheatley $K$, Brookes CL, Howman AJ, et al: Prognostic factor analysis of the survival of elderly patients with $A M L$ in the MRC AML11 and LRF AML14 trials. Br J Haematol 145:598-605, 2009

42. Breems DA, Van Putten WL, Huijgens PC, et al: Prognostic index for adult patients with acute myeloid leukemia in first relapse. J Clin Oncol 23: 1969-1978, 2005

43. Ringdén $O$, Pavletic SZ, Anasetti $C$, et al: The graft-versus-leukemia effect using matched unrelated donors is not superior to HLA-identical siblings for hematopoietic stem cell transplantation. Blood 113:3110-3118, 2009

44. Kahl C, Storer BE, Sandmaier BM, et al: Relapse risk in patients with malignant diseases given allogeneic hematopoietic cell transplantation after nonmyeloablative conditioning. Blood 110: 2744-2748, 2007

45. Schnittger S, Kern W, Tschulik C, et al: Minimal residual disease levels assessed by NPM1 mutation-specific RQ-PCR provide important prognostic information in AML. Blood 114:2220-2231, 2009

\section{Sign up for Alerts About Your Topic of Interest Learn about new research in your field as it becomes available. Subscribe to a JCO e-mail alert to be notified immediately when new articles within your area of interest are posted.}

\section{Receive notification when:}

$J C O$ releases a new issue's Table of Contents.

A new issue of $J C O$ is posted online.

$>$ New articles are published online ahead of print publication.

$>$ New content in your subspecialty is published.

D An article is published online from an author of interest.

Go to jco.org/alerts to sign up. 